\title{
Development and in-vitro characterization of an implantable flow sensing transducer for hydrocephalus
}

\author{
Toralf Bork • Andreas Hogg • Markus Lempen • Daniel Müller • Damien Joss • \\ Thibaut Bardyn • Philippe Büchler • Herbert Keppner • Stephan Braun • \\ Yanik Tardy $\cdot$ Jürgen Burger
}

Published online: 13 March 2010

(C) Springer Science+Business Media, LLC 2010

\begin{abstract}
An implantable transducer for monitoring the flow of Cerebrospinal fluid (CSF) for the treatment of hydrocephalus has been developed which is based on measuring the heat dissipation of a local thermal source. The transducer uses passive telemetry at $13.56 \mathrm{MHz}$ for power supply and read out of the measured flow rate. The in vitro performance of the transducer has been characterized using artificial Cerebrospinal Fluid (CSF) with increased protein concentration and artificial CSF with $10 \%$ fresh blood. After fresh blood was added to the artificial CSF a reduction of flow rate has been observed in case that the sensitive surface of the flow sensor is close to the sedimented erythrocytes. An increase of flow rate has been observed in case that the sensitive surface is in contact with the remaining plasma/artificial CSF mix above the sediment which can be explained by an asymmetric flow
\end{abstract}

T. Bork $\cdot$ A. Hogg $\cdot$ Y. Tardy $\cdot$ J. Burger $(\bowtie)$

Codman Neuro Sciences sarl,

Rue Girardet 29,

2400 Le Locle, Switzerland

e-mail: jburger@its.jnj.com

M. Lempen · D. Müller

Bern University of Applied Sciences,

Biel, Switzerland

D. Joss $\cdot$ H. Keppner

Neode, Haute Ecole ARC Ingénierie,

La Chaux-de-Fonds, Switzerland

T. Bardyn · P. Büchler · J. Burger

Institute for Surgical Technology and Biomechanics ISTB,

University of Bern,

Bern, Switzerland

S. Braun

Sensirion $A G$,

Staefa, Switzerland profile caused by the sedimentation of erythrocythes having increased viscosity compared to artificial CSF. After removal of blood from artificial CSF, no drift could be observed in the transducer measurement which could be associated to a deposition of proteins at the sensitive surface walls of the packaged flow transducer. The flow sensor specification requirement of $+-10 \%$ for a flow range between $2 \mathrm{ml} / \mathrm{h}$ and $40 \mathrm{ml} / \mathrm{h}$. could be confirmed at test conditions of $37^{\circ} \mathrm{C}$.

Keywords Neurosurgery · Hydrocephalus · Calorimetric flow sensor $\cdot$ Biocompatible packaging $\cdot$ Passive telemetry

\section{Introduction}

Hydrocephalus is one of the most common congenital disorders of the central nervous system. Hydrocephalus may also develop after birth and may be caused by secondary damage to the brain caused by hemorrhage, stroke, infection, tumor, or traumatic injury. Normal Pressure Hydrocephalus NPH, in which the pressure of CSF may not be elevated, is a form of chronic hydrocephalus that typically occurs in adults who are 60 years and older. It is characterized by clinical symptoms of dementia, gait disturbance (i.e., difficulty walking), and urinary incontinence (Black et al. 1985). While the symptoms associated with NPH can intensify over time if the condition is left untreated, if treated properly, the dementia associated with NPH can be reversed.

Hydrocephalus occurs when there is an imbalance between the amount of CSF that is produced and the rate at which it is absorbed. Cerebrospinal Fluid (CSF) is produced by secretory cells of the choroid plexus at a rate of approximately $20 \mathrm{ml}$ per hour, circulates through the 
ventricular system and is finally absorbed into the venous system via the superior sagittal sinus. The occurrence of hydrocephalus in newborn children is about 1 out of 5002,000 (Murshid et al. 2000; Persson et al. 2007).

The treatment of hydrocephalus requires the implantation of a catheter for fluid drainage. Per year, more than 100,000 shunt valves are implanted worldwide. However, malfunctioning of the shunt catheter cannot be excluded which might lead to severe complications especially for children (Oikonomou et al. 1999).

Shunt blockage occurrence ranges from $20 \%$ to $30 \%$ within the first year after implantation. In order to diagnose a shunt system, an invasive procedure is often required and as with any invasive procedure, the risk to the patient is increased. When the diagnostic gives questionable results, the shunt system will be replaced and this sometimes leads to unnecessary surgical procedures that further impact the patient and increases the cost of patient care.

In the case of NPH, improvement of patient conditions by implantation of a shunt valve has been achieved in 30 $50 \%$ of patients (Vassilouthis 1984). However, the implantation of a shunt valve to divert excessive CSF carries a complication rate of approximately $40 \%$ (Vanneste et al. 1992; Vanneste 2000) in case of NPH of which $20 \%$ are severe (Vanneste 2000), mostly due to over-drainage (Larsson et al. 1991).

In order to monitor in-vivo intracranial conditions, micromachined capacitive pressure sensors with telemetric communication have been developed (Ko et al. 1981; Munshi et al. 1998; Ginggen et al. 2008).

In contrast to pressure monitoring, flow sensing would provide a direct method to monitor patency of the shunt valve as well as to capture physiological relevant variations of CSF flow. Furthermore, there is a need for intelligent shunts that are able to dynamically adjust to varying operating conditions and thereby reduce the number of shunt revisions a patient has to undergo. Implantable flow sensors for monitoring of hydrocephalus would represent one essential component of future intelligent shunt valves.

However, flow sensing of CSF is currently done using MRI methods (Linninger et al. 2007) which are costly, time-consuming and not readily accessible on short notice.

Another method to get information of CSF flow in the ventricular system is by using computational fluid dynamics methods (CFD). Kurtgluoclu et al. have shown that by combination of anatomic, velocimetric and magnetization modulated MRI scans with CFD simulations, it is possible to reconstruct the CSF flow field in the third brain ventricle and the aqueduct of Sylvius (Kurtcuoglu et al. 2007).

CSF flow from the peritoneal end of a ventriculoperitoneal (V-P) shunt was detected by means of Doppler ultrasonography. Although in general, clear CSF is not ultrasonically visible, the presence of choroid plexus debris was assumed to provide ultrasonic contrast in some cases (Sgouros et al. 1996).

The first objective of this study was to develop a calorimetric flow transducer, which can be positioned close to the shunt valve and implanted in the patients. The sensor must be fully biocompatible and communicate flow measurements to the clinician by passive telemetry. The second aim was to perform in-vitro test of this flow sensor to quantify the effect of CSF proteins deposition on the general performance of the device and on the accuracy of flow measurements.

The flow transducer allows an improved long-time monitoring of the functioning of the valve and allows a better understanding of the flow of CSF under varying physiological conditions of the patient. An improved management of hydrocephalus shunted patients will be possible by avoiding conditions of over- and underdrainage of CSF.

\section{Materials and methods}

The micromachined implantable transducer with the streamline integrated fluid channel is placed into the peritoneal or atrial catheter close to the Hydrocephalus shunt valve by gluing it into a silicone housing which will be sealed with silicon lips at the edge. A polymer plate will be applied to hold the transducer in place. An external reader supplies the transducer with energy and reads the data from the implanted transducer by passive telemetry. The external reader is coupled to a Bluetooth transceiver which transmits the transducer data to an external computer or battery powered PDA for data storage, -display and processing (Fig. 1).

\subsection{Transducer description}

The implantable transducer consists of three main parts: a calorimetric flow sensor based on a thermal anemometer principle (Lammerink et al. 1993; Mayer et al. 1997), a microcontroller and a RF section (Fig. 2). The flow sensor (Sensirion AG, Stäfa, Switzerland) is realized on a CMOS silicon chip that contains the sensor as well as all necessary electronics to treat the sensor signal (ADC, linearization, amplification, temperature compensation, calibration memory) (Mayer et al. 2004). The sensors have been calibrated using water as medium with a specification requirement of $+-10 \%$ for a flow between $2 \mathrm{ml} / \mathrm{h}$ and $40 \mathrm{ml} / \mathrm{h}$.

The flow channel is formed by sandwiching 2 glass wafers. The bottom wafer of $1.4 \mathrm{~mm}$ thickness has a rectangular channel with dimensions $0.9 \mathrm{~mm} \times 0.9 \mathrm{~mm}$ formed by dicing saw cutting to which a $0.1 \mathrm{~mm}$ thick top glass wafer is bonded. 
Fig. 1 Overview of the implantable transducer for flow sensing of hydrocephalus including implantable transducer with calorimetric flow sensor and passive telemetry for power supply and data communication via external reader. Flow data can be displayed on the reader as well as on an external computer via Bluetooth



In order to provide the implant with energy and to read out the measured flow rate, RF passive telemetry is used at a RF frequency of $13.56 \mathrm{MHz}$ (Neukomm et al. 2003; Schnakenberg et al. 2000). The RF section of the implant is responsible for extracting energy for the implant, for transmitting the level of RF induced voltage to the microcontroller (Silabs C8051F300) as well as for modulating the FSK signal for communication with the external reading unit. Modulation frequencies at $109 \mathrm{kHz}$ for a logic 0 and

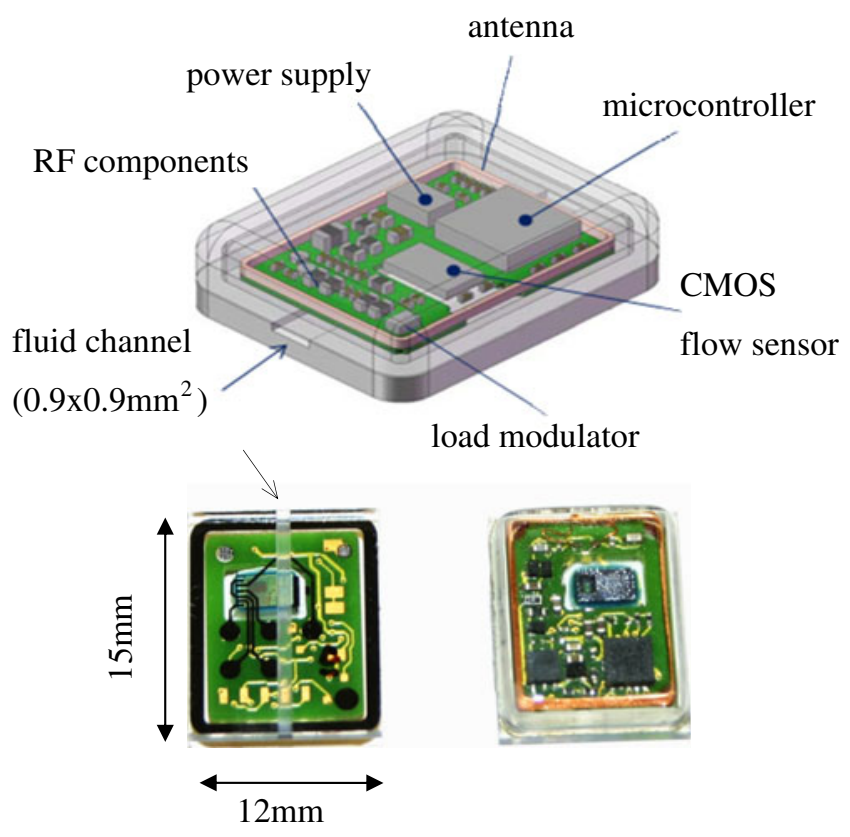

Fig. 2 Components of the implantable calorimetric flow transducer. The height of the encapsulated implant is $4.5 \mathrm{~mm}$. Bottom left: Bottom view of the packaged sensor showing the rectangular flow channel. Bottom right: Top view of the packaged flow sensor
$117 \mathrm{kHz}$ for a logic 1 are applied to the load modulating circuit at V1 by the microcontroller (Fig. 3).

In order to reduce the energy dissipated in the implant, the modulation pulse width of the microcontroller had to be minimized. Since the microcontroller only generates FSK modulation frequencies with $50 \%$ duty cycle, an additional capacitor $\mathrm{C}_{11}$ was used to adjust the modulation pulse with. If the pulse width is selected too large, too much energy is dissipated in the load resistor $\mathrm{R}_{3}$ and the telemetric reading range is decreased. However if the pulse width is too small, the FSK signal is too weak and the modulation cannot be detected by the external reading unit. It was found that a duty cycle of about $15 \%$ to $20 \%$ gives optimal results.

In order to minimize the height of the implant, a diode D1 is used in the load modulator instead of an inductivity as used in common passive telemetry systems. The energy drawn from the magnetic field supplied by the external reading unit is stored in a large capacitance $C_{12}$ in order to ensure stable power supply of sensor and microcontroller during active load modulation.

The load resistor $\mathrm{R}_{3}$ was chosen as small as possible to achieve a maximal load modulation amplitude. On the other side, the minimal value of $\mathrm{R}_{3}$ was limited by the maximum collector current of $\mathrm{V} 1$.

The power consumption of the CMOS flow sensor was measured to be $16.3 \mathrm{~mW}$ in measuring mode at a supply voltage of $3.3 \mathrm{~V}$. Taking into account the power consumption of the ultra-low power microcontroller of $2.87 \mathrm{~mW}$ at a supply voltage of $3.3 \mathrm{~V}$, the minimal energy needed for supply of the implant is $19.17 \mathrm{~mW}$. As the output voltage of the RF-DC varies according to the distance between antennas of reading unit and implant as well as external power supplied, the voltage of the RF-DC converter is passed to a voltage regulator (TPS715A33) which regulates 


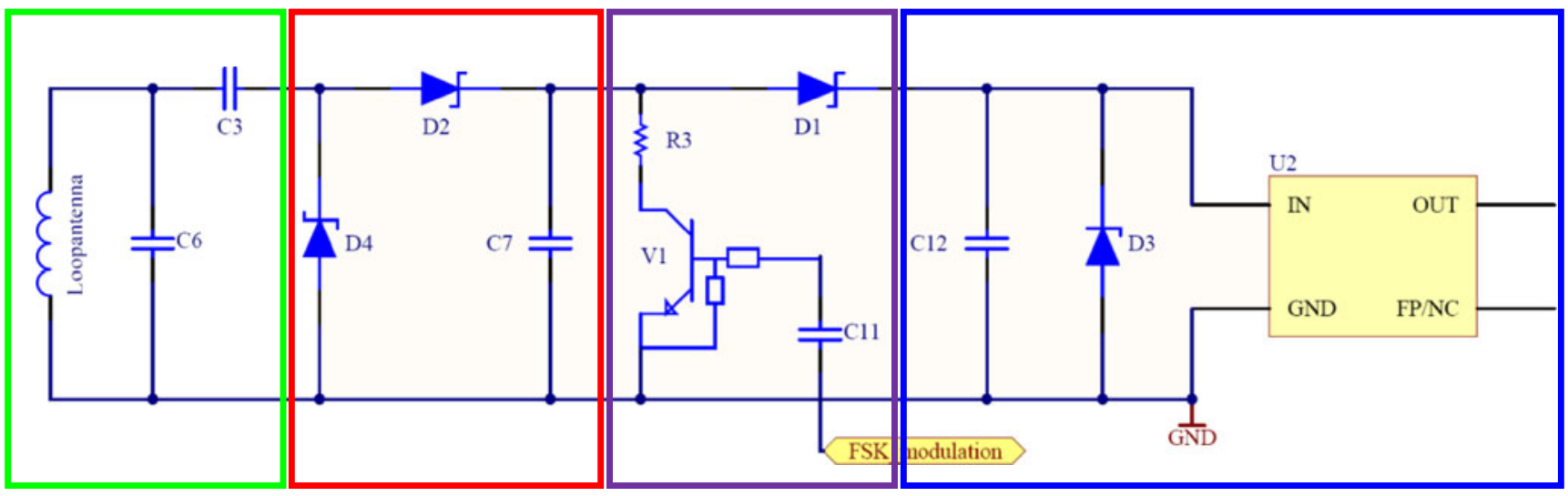

Fig. 3 Transducer telemetry electronics. Green: Loop antenna and impedance matching. Red: RF-DC Converter. Purple: Load modulator. Blue: DC supply

the supply voltage input to the microcontroller and the CMOS flow sensor to $3.3 \mathrm{~V}$.

\subsection{External reading unit}

The external reading unit is used to supply the implant with energy and to acquire the flow measurement data. Using a maximum transmission power of $3 \mathrm{~W}$ of the external reading unit, the induced voltage at the RF-DC converter of the transducer implant could reach voltages up to $16 \mathrm{~V}$ with reader antenna and implant at a distance of $2 \mathrm{~mm}$ and voltages up to $10 \mathrm{~V}$ at a common working distance of $17 \mathrm{~mm}$ between antennas of external reader and transducer, which, at a distance of $17 \mathrm{~mm}$, would lead to a power dissipation of up to $60 \mathrm{~mW}$ and a temperature increase in the implant from $37^{\circ} \mathrm{C}$ up to $41.2^{\circ} \mathrm{C}$.

In order to reduce excessive heating of the implant, the induced voltage of the RF-DC converter is measured by the microcontroller and transmitted to the external reader where its transmission power is adjusted accordingly (Fig. 4). This way, the maximum RF-DC voltage is kept constant at a voltage of $5 \mathrm{~V}$ and the total energy dissipated in the implant sums up to $29.05 \mathrm{~mW}$ leading to a measured temperature increase in the implant from $37^{\circ} \mathrm{C}$ to $39^{\circ} \mathrm{C}$ which corresponds to the maximum allowable temperature increase of an active implant in operating conditions [International Standards Organisation (ISO) 14708-1 (2000)].
One of the main problems of the use of passive telemetry in implants for simultaneous energy supply and data communication is the controlled power-up of the implant as the microcontroller and flow sensor need a minimal slew rate of the supply voltage when started which cannot be reached if the RF field of the external reader is approached only slowly to the implant. This problem has been solved by software in the external reader where a microcontroller verifies the incoming data packages. If no valid data packages are demodulated by the reading unit or the incoming data has transmissions errors, it is assumed that the provided RF field is not strong enough to feed the sensor and microcontroller. In this case the RF field is switched off for $20 \mathrm{~ms}$ and on for $300 \mathrm{~ms}$ periodically until the RF field at the implant has sufficient amplitude to provide a sufficiently steep slope for the supply voltage. This process also treats problems if the connection breaks down for other reasons like no proper alignment of antennas.

\subsection{Packaging of the transducer and biocompatibility}

One of the key features of the transducer is the calorimetric flow measurement which is done through the borosilicate glass substrate of 100 um thickness. Using this configuration, the temperature sensors and the heaters are not directly exposed to the body fluids. Therefore, no coating or passivation of the sensors and heaters is needed and

Fig. 4 Energy supply and communication between external reader and implanted transducer. In order to minimize the power dissipated in the implant, the RF power of the reader is adjusted to keep the supply voltage at the input of the voltage regulator of the implanted transducer constant

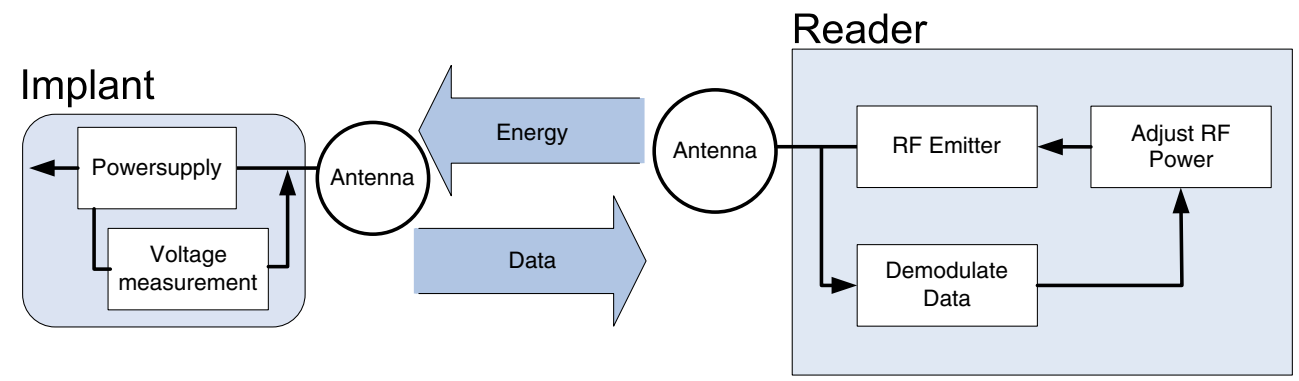


electrical feed-throughs to the fluidic chamber are avoided. In that way, a highly reliable and long-term biocompatible implant could be realized which is especially important as the transducer will remain inside the body for up to 10 years or even longer (Bork 2007).

In order to provide a leak-tight packaging of the implant, a low-temperature brazing process is used to join a borosilicate glass base plate and a borosilicate glass cap (Ginggen 2003) (Fig. 5). The Base plate which includes the flow channel and carries the PCB with the transducer electronics as well as the glass cap are metallised by sputtered $\mathrm{Ti}(100 \mathrm{~nm}) / \mathrm{Au}(2,000 \mathrm{~nm})$ rings. An eutectic SnInAg alloy (Sn77.25 In20 Ag2.8, melting temperature $184^{\circ} \mathrm{C}$ ) brazing ring with a thickness of $50 \mu \mathrm{m}$ is used to join the metallisations of glass cap and glass base plate.

The brazing rings are cut using a Nd:YAG nanosecond laser (pulse duration $<25 \mathrm{~ns}$ ) at $355 \mathrm{~nm}$ using a laser spot diameter of $20 \mu \mathrm{m}$ and a power of $2 \mathrm{~W}$.

However, the brazing ring used to encapsulate the implant modifies the inductivity of the implant antenna by mutual inductive coupling. In addition, it represents a short circuited metallic conductor which, in close proximity to the implant antenna, induces additional eddy currents in the brazing ring where part of the RF energy is be dissipated. In order to minimize the energy dissipated in the brazing ring, the distance of the implant antenna to the brazing ring has been increased to a distance of $0.7 \mathrm{~mm}$ (Figs. 6 and 7). Taking a maximal power of the external reading unit of $3 \mathrm{~W}$ and an energy of $29.05 \mathrm{mV}$ dissipated in the implantable transducer at a voltage of the RF-DC converter of $5 \mathrm{~V}$, a maximal allowed damping of the antenna system responsible for RF energy transmission of $-20 \mathrm{~dB}$ can be deduced.

In Fig. 7, the RF energy transfer characteristics of the reader and transducer antenna system is shown. At a distance of $0.7 \mathrm{~mm}$ between brazing ring and lower edge of the implant antenna, a maximal allowed damping of

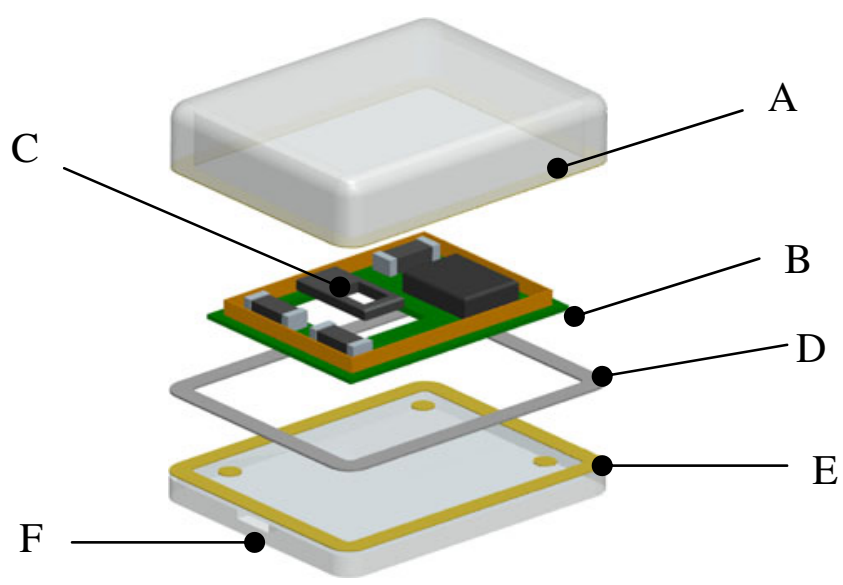

Fig. 5 Packaging of the implantable transducer. Implant assembly. $A$ : Glass cap, $B$ : Electronics with antenna, $C$ : Flow sensor, $D$ : Braze ring, $E$ : Glass base plate, $F$ : Flow channel

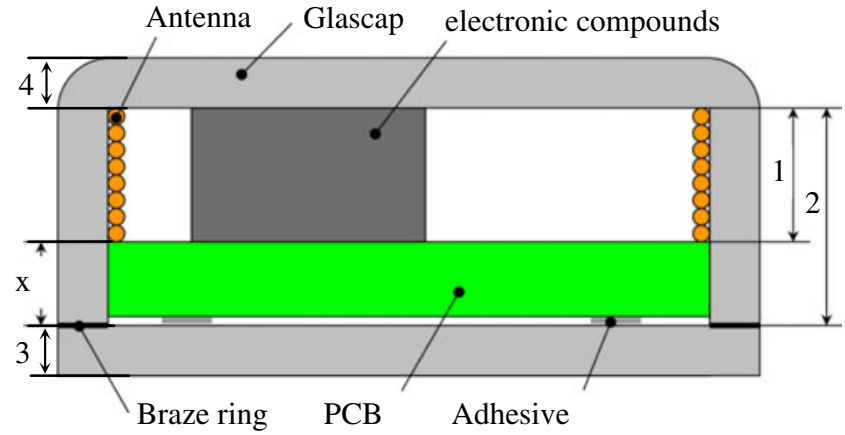

Fig. 6 Positioning of the transducer antenna in the implant to minimize influence from brazing ring. In order to reach an overall height of the implantable transducer of $4.5 \mathrm{~mm}$, the total height available for the electronics inside the implant capsule (2) is limited to $2 \mathrm{~mm}$. The maximal height of the antenna and the electronic components mounted on the Printed Circuit Board (PCB) is $1 \mathrm{~mm}$ (1). Taking into account the thickness of the adhesive of about $0.2 \mathrm{~mm}$, the distance between antenna and brazing ring (x) can be adjusted to $0.7 \mathrm{~mm}$ max. leaving a tolerance of $0.1 \mathrm{~mm}$ (the bottom glass substrate and the top glass cap have a thickness of $1.5 \mathrm{~mm} \mathrm{(3)}$ and $1 \mathrm{~mm}(4))$

$-20 \mathrm{~dB}$ leads to a maximal communication distance between external reader antenna and implant antenna of about $37 \mathrm{~mm}$. This distance is sufficient for a reliable communication with the implant as the implant will be implanted subcutaneously into the skull behind the ear.

\subsection{In-vitro characterization of the implantable flow} transducer

\subsubsection{Test liquids for characterisation of protein adsorption}

The clinical significance of elevated protein levels in cerebrospinal fluid (CSF), its impact on implants like shunt valves, and the comparative tolerance of specific shunt systems to an elevated CSF protein level has been the subject of discussion for many years. The consensus view being until recently is that to shunt a patient whose CSF protein level was high was to risk shunt blockage and infection. Protein deposition from "normal" CSF is slow, but it was shown that a range of proteins (vitronectin, fibronectin and fibrinogen) was eventually deposited on the inner surface of shunts immediately after insertion (Lundberg et al. 1999).

However, it was shown that the thin protein film that accumulates on shunt catheters is not sufficient to cause obstruction. The major protein in this film was shown to be albumin (Brydon et al. 1998).

Calorimetric flow sensors with temperature sensing and heating elements attached to the walls of the fluid channel are sensitive to modifications of the sensing surface area.

A potential protein or blood component adsorption especially during the first days after implantation with a 
Fig. 7 Transfer characteristics of the transducer telemetry without braze ring (blue and red) as well with braze ring of the transducer. At a distance $\mathrm{x}$ of $0.7 \mathrm{~mm}$ between brazing ring and lower edge of the implant antenna (see also Fig. 6), a damping of $-20 \mathrm{~dB}$ leads to a maximal communication distance of about $37 \mathrm{~mm}$



Distance antenna - braze ring $\times$ [mm] risk of elevated protein concentration and blood within the CSF could have an influence on the flow sensor response.

In order to investigate the sensor performance under worst case situations, the flow rate of the sensor was measured using elevated protein concentration and blood content in CSF.

The composition of normal CSF is close to that of ultrafiltrate of plasma and has a protein concentration of less than $0.5 \%$ of that of plasma (Kuschinsky 1996). The normal adult range of protein content in the CSF ranges between $0.15 \mathrm{~g} / 1$ and $0.45 \mathrm{~g} / 1$ (Davson and Segal 1996; Critchley et al. 1972).

However, CSF protein content varies with age and is known to decline over the first few months of life (Widell 1958). Elevated protein content in CSF may be indicative of a pathologic process and levels above $1.0 \mathrm{~g} / \mathrm{l}$ in neonates and $0.35 \mathrm{~g} / 1$ in preadolescent children can be reached (Wong et al. 2000).

In order to take into account even pathologic levels of protein concentrations in CSF and to accelerate the protein absorption, artificial CSF with a protein concentration that was increased by a factor of 10 to reach $2 \mathrm{~g} / 1$ was prepared according to Table 1 and used in the in-vitro tests.

Due to patients who have hydrocephalus as a result of a haemorrhagic event such as periventricular haemorrhage in the premature neonate, or subarachnoid haemorrhage in the adult, CSF containing a profile of proteins different from that of "normal" CSF must be taken into consideration as well.

For the testing, the following solutions were used:

- $\quad$ artificial CSF with $2 \mathrm{~g} / \mathrm{l}$ protein (Albumin from human serum)

- $\quad$ artificial CSF with $2 \mathrm{~g} / \mathrm{l}$ protein (Albumin from human serum) and $10 \%$ fresh blood

- sterile water with $0.65 \%$ Sodium azide as reference solution

In order to simulate a potential protein deposition that might affect the sensor function after e.g. a subarachnoid haemorrhage, fresh human blood was drawn from a vein and added immediately to the warmed artificial CSF solution in order to avoid clotting. As the mixture tends to
Table 1 Composition of artificial Cerebrospinal fluid

\begin{tabular}{llc}
\hline Chemical Name & Formula & Conc. in CSF [g/L] \\
\hline Sodium chloride & $\mathrm{NaCl}$ & 8.660 \\
Potassium chloride & $\mathrm{KCl}$ & 0.224 \\
Calcium chloride dihydrate & $\mathrm{CaCl}_{2}-2 \mathrm{H}_{2} \mathrm{O}$ & 0.206 \\
Magnesium chloride hexahydrate & $\mathrm{MgCl}_{2}-6 \mathrm{H}_{2} \mathrm{O}$ & 0.163 \\
Sodium phosphate monobasic monohydrate & $\mathrm{NaH}_{2} \mathrm{PO}_{4}-\mathrm{H}_{2} \mathrm{O}$ & 0.027 \\
Di-Sodium hydrogen phosphate heptahydrate, acs & $\mathrm{Na}_{2} \mathrm{HPO}_{4}-7 \mathrm{H}_{2} \mathrm{O}$ & 0.214 \\
Sodium Azide 0.1 M Solution & $\mathrm{N}_{3} \mathrm{Na}_{2}$ & $5 \mathrm{~g}$ or $0.77 \mathrm{ml}$ \\
D-(+)-Glucose & $\mathrm{C}_{6} \mathrm{H}_{12} \mathrm{O}_{6}$ & 0.600 \\
Urea & $\mathrm{CH}_{4} \mathrm{~N}_{2} \mathrm{O}$ & 0.201 \\
Albumin (from human serum) & & 2.000 \\
Gamma-globulin from human blood & & 0.015 \\
\hline
\end{tabular}


degrade after about $24 \mathrm{hrs}$ at $37^{\circ} \mathrm{C}$ due to break up of erythrocytes, the solution was changed daily.

\subsubsection{Fluidic test setup}

The fluidic circuit for characterization of the implantable flow sensors consists of a tubing pump which pulls the test liquids artificial CSF, artificial CSF with $10 \%$ fresh blood and sterile water with $0.65 \%$ Sodium azide as reference solution through three parallel fluidic circuits (Fig. 8). Sodium azide is used as a preservative for sterile water to prevent growth of bacteria. The test setup was kept in an oven at $37^{\circ} \mathrm{C}$. The scale reading was taken in parallel and the flow was calculated by taking the start reading and the end reading of the balance. Taking the flow measurement of the scale as the point of reference, a relative flow rate in $\%$ was calculated by taking

$$
\frac{\text { flow rate (flow sensor) - flow rate (scale) }}{\text { flow rate }(\text { scale })} \cdot 100
$$

In order to simulate a continuous use of the flow sensor during the test period of 26 days, the heater of the flow sensor was periodically turned on for 5 minutes and then turned off for 10 minutes in between the scale measurements. The test period of 26 days was chosen base on the observation of Baird et al. that perfusion of hydrocephalus valves with solutions of dilute whole blood showed effects on the perfusion pressure of the valves due to adsorption effects after within their test period used of 14 days (Baird et al. 2002).

The tubing diameter of the fluidic test system has been selected to be $1.02 \mathrm{~mm}$.

The peristaltic pump has been used in a mode pulling fluid through sensors in order to reduce pulsation ripples in the fluidic system created by the rollers of the peristaltic pump. Once a day, the measurements of the sensors have been compared to a scale where a measurement time of $180 \mathrm{~s}$ and a sampling frequency of $10 \mathrm{~Hz}$ has been used. For that purpose, the fluidic channel to the scale which normally is disconnected from the pumping circuit by a two-way valve, was primed using a syringe pump. Then, each of the three fluidic circuits was interrupted subsequently and opened to the scale. In order to evaluate the flow rate by the scale measurement, the weight of the liquid was linearly fitted as a function of time.

\section{Results and discussion}

In Fig. 9 the relative flow rate for all sensors for a test period of 26 days is shown as the difference between the flow sensor measurement and the comparative scale measurement. Within those 26 days the flow rate has been varied from the nominal flow of $20 \mathrm{ml} / \mathrm{h}$ down to $2.5 \mathrm{ml} / \mathrm{h}$ and up to $50 \mathrm{ml} / \mathrm{h}$ in order to characterize the relative flow rate of the flow sensors at different flow rates within the operating range. It can be seen that there is no apparent drift in any of the three fluidic circuits, especially when only comparing the beginning and the end of the testing where the $20 \mathrm{ml} /$ day flow rate was tested.

The average of all relative flow rates (261 values) shown in Fig. 9 is offset by $-5.4 \%$ for a test temperature of $37^{\circ} \mathrm{C}$. As the flow sensors have been calibrated at a temperature of $22^{\circ} \mathrm{C}$, the influence of temperature on the difference between the scale measurements and the flow sensor measurements was evaluated.

For that purpose, the oven containing the fluidic setup has been adjusted to $22^{\circ} \mathrm{C}$ and $37^{\circ} \mathrm{C}$ and 3 sensors have been characterized at 2 different flow rates of $5 \mathrm{ml} / \mathrm{h}$ and $10 \mathrm{ml} / \mathrm{h}$ at temperatures $22^{\circ} \mathrm{C}$ and $37^{\circ} \mathrm{C}$. The temperature
Fig. 8 Test setup for in-vitro characterisation of the implantable flow transducer. Only one fluidic circuit is shown




Fig. 9 Relative flow rate of the implantable calorimetric flow sensor as a function of time. In flow circuit 3 (sensors 31, 32, 33), artificial CSF was temporarily replaced by artificial CSF $+10 \%$ fresh blood as indicated by the dotted lines

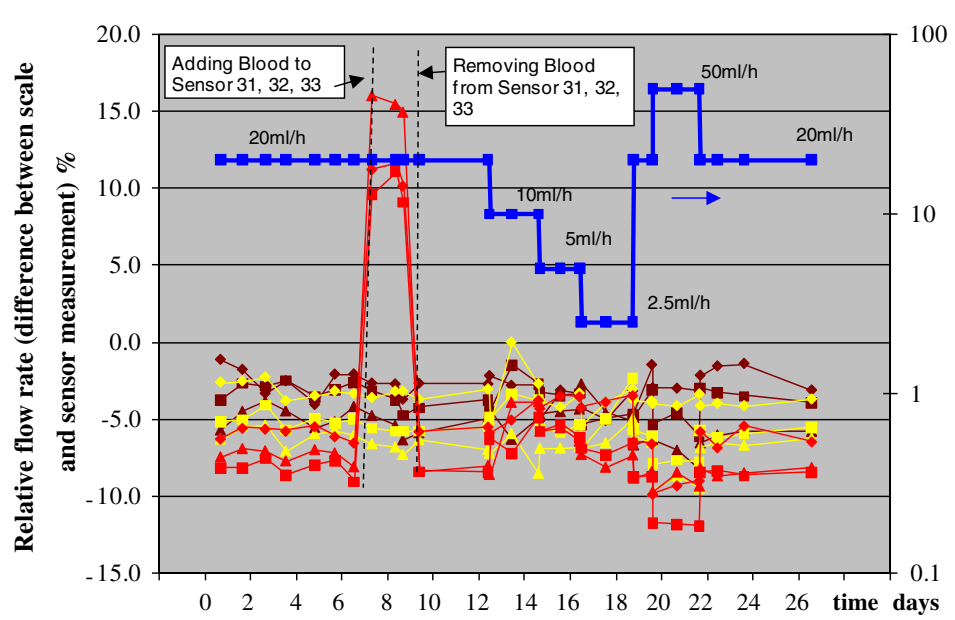

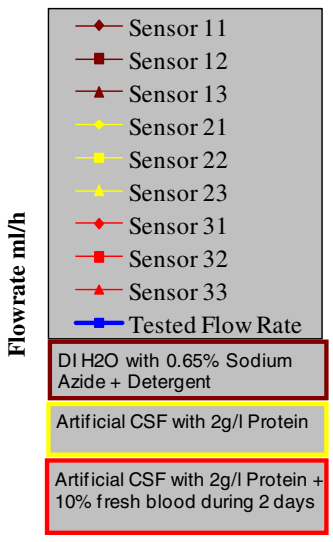

offset of the relative sensor flow rates at $37^{\circ} \mathrm{C}$ is about $6.3 \%$ compared to the relative sensor flow rates at $22^{\circ} \mathrm{C}$.

A temperature compensation of the offset of $-5.4 \%$ at $37^{\circ} \mathrm{C}$ with the temperature offset of $+6.3 \%$ leads to a compensated average of all relative flow rates of $+0.9 \%$.

The reference liquid containing sensors (brown in Fig. 9) as well as the CSF/protein containing sensors (yellow in Fig. 9) are maintaining essentially the same difference between sensor and scale measurements throughout the test.

Only the sensors of the fluidic circuit that had temporarily $10 \%$ fresh blood added to it (red in Fig. 9) show an increase of relative flow rate of $\sim 20 \%$ to $\sim 25 \%$ during the time the blood is present.

In order to test the dependency influence of the sensor reading with respect to the sensor position/orientation the original setup has been modified so that the sensors could be mounted in different positions/orientations as described in Fig. 10. For this test, a constant flow rate of $20 \mathrm{ml} / \mathrm{h}$ was used. After each position/orientation change of the sensor, a time of $15 \mathrm{~min}$ was used to allow for a stabilization of the fluidic system before measurement.

Looking at the data of Fig. 11 during the time when 10\% fresh whole blood was present in the artificial CSF, one can see that for the two measurements where the sensors are mounted horizontally with the sensors on the top of the flow channel, the adding of fresh blood changed the average relative flow rate from an average flow rate without blood of $-7.4 \%$ ("Horizontal sensor UP") to $+12.3 \%$ ("Horizontal sensor Blood UP 1") and to $+7.0 \%$ ("Horizontal sensor Blood UP 2"). After blood was removed from the artificial CSF, the sensor reading came back to an average relative flow rate of $-7.4 \%$. For the position- and orientation depending measurements shown in Fig. 11, a nominal flow rate of $20 \mathrm{ml} / \mathrm{h}$ was used.

In case the sensor is flipped and is located below the flow channel ("Horizontal Sensor Blood DOWN" in Fig. 11), the relative flow rate is decreased from an average flow rate without blood of $-7.8 \%$ to an average of $-60.7 \%$.

Finally, the sensors were mounted in a vertical position with the flow either going up- or downwards giving

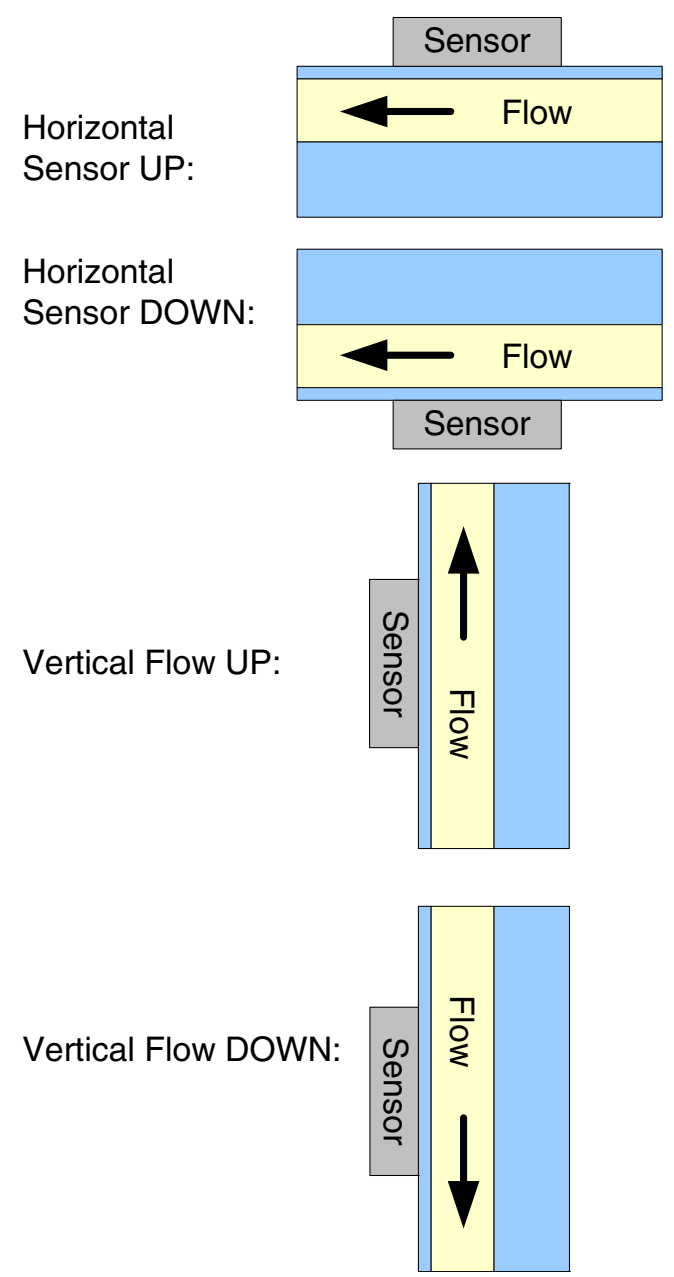

Fig. 10 Description of the position and orientation of the flow sensor with respect to the flow used for measurements shown in Fig. 11 
average relative flow rates of $-9 \%$ ("Vertical Flow Blood UP") and $-2.6 \%$ ("Vertical Flow Blood DOWN"). After the CSF/blood mixture has been removed and replaced by artificial CSF, the average sensor measurements of sensors 31,32 and 33 in Fig. 11 show a relative flow rate of $-7.5 \%$ which corresponds to the relative flow rate before blood was added to the fluidic system. The configurations "Vertical Flow Blood UP" "Vertical Flow Blood DOWN" should show the same flow speed as in both cases no sedimentation of erythrocytes should occur. The observed difference of relative flow rates can be explained by the fact that, the liquid in the flow channels was still not homogeneously mixed which could also be confirmed visually.

Comparing the relative flow rates before and after the blood was added/removed in Fig. 9, even the flow sensors in the fluidic circuit with artificial CSF and $10 \%$ blood don't exhibit a drift. Furthermore when looking at Fig. 9 one can see that there is no major influence on the relative flow rate when tested between $2.5 \mathrm{ml} /$ day and $50 \mathrm{ml} /$ day. All measured differences between sensor and scale measurements for all sensors remain within $0 \%$ to $-10 \%$ except sensor 32 with $\sim-12 \%$ during the $50 \mathrm{ml} /$ day measurement. This deviation might be explained by a misaligned fluidic connection it was found to be very important to have a laminar flow at the sensor location which is depending on the fluidic connection and the flow rate used.

The data of sensors $11,12,13$ (deionized $\mathrm{H}_{2} \mathrm{O}$ with $0.65 \%$ sodium azide), and of sensors 21,22 and 23 (artificial CSF with $2 \mathrm{~g} / 1$ proteins) in Fig. 11 show that when no blood is present in the fluid the influence of the position/orientation on the sensor reading can be neglected. All data points for any of the positions/orientations of these sensors are within a range of $-2 \%$ to $-8 \%$.

The observed effects of flow rate when blood is added to artificial CSF can be explained by the settling of the heavier erythrocytes on the bottom of the flow channel due to the low flow rate used. This sedimentation could be observed visually in the channel tubing and can basically influence the performance of the anemometric flow sensor via a change of thermal conductivity of the medium close to the heater and sensors or via a change of viscosity and thus change of the speed of flow close to the sensing surface.

As shown in Fig. 12, the response of the sensor strongly depends on the thermal conductivity of the liquid which is in contact with its heater and temperature sensors. The calibration curves of the calorimetric sensor for water with a thermal conductivity of $\left(\kappa_{\text {Water }}=0.6 \mathrm{~W} /(\mathrm{m} \cdot \mathrm{K})\right.$ and of methanol with a lower thermal conductivity of $\left(\mathrm{K}_{\text {Methanol }}=\right.$ $0.21 \mathrm{~W} /(\mathrm{m} \cdot \mathrm{K})$ shows a raw sensor signal of $-8,200$ a.u. for water compared to $-2,760$ a.u. for methanol. As the sensor used for the measurement shown in Figs. 9 and 11 uses an internally stored calibration curve for water, the use of a liquid with a thermal conductivity different from water would impact the sensor reading accordingly.

As the thermal conductivity $\mathrm{K}$ of whole human blood with $0.49 \mathrm{~W} /(\mathrm{m} \cdot \mathrm{K})$ is smaller than that of CSF with $0.63 \mathrm{~W} /(\mathrm{m} \cdot \mathrm{K})(\mathrm{Neff} 2005)$, the thermal conductivity of the sediment in contact with the sensor in case "Horizontal Sensor Blood DOWN" in Fig. 11, will be reduced. The thermal conductivity of the mixture of artificial CSF with plasma in contact with the sensor in case of "Horizontal Sensor Blood UP $1 / 2$ " is close to that of CSF as the thermal conductivity of plasma is close to CSF ( $\kappa_{\text {Plasma }}=0.57 \mathrm{~W} /$ $(\mathrm{m} \cdot \mathrm{K})$, (Balasubramaniam and Bowman 1977)) and therefore the sensor signal should not be influenced by thermal properties of the liquid in this position of the sensor. However, the relative flow rate increased by an average of $+17 \%$ compared to the scale reference measurement with the sensor on the top of the flow channel which indicates an increased velocity of the liquid.
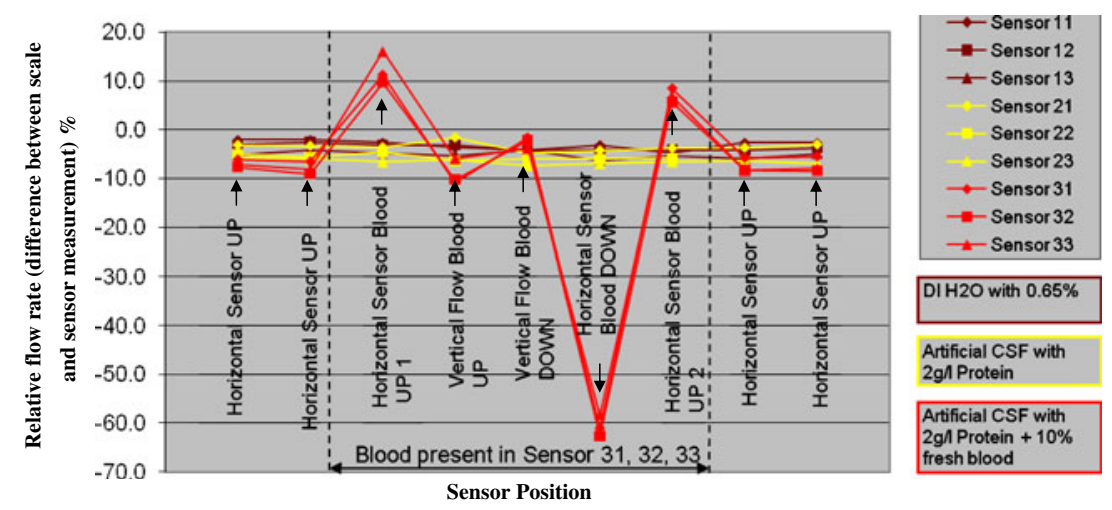

Fig. 11 Relative flow rate depending on the position and orientation of the flow sensor with respect to the flow channel as defined in Fig. 10. In flow circuit 3 (sensors 31, 32, 33), artificial CSF was temporarily replaced by artificial CSF $+10 \%$ fresh blood as indicated by the dotted lines. A nominal flow rate of $20 \mathrm{ml} / \mathrm{h}$ has been used. After each position/orientation change of the sensor, a time of $15 \mathrm{~min}$ was used to allow for a stabilization of the fluidic system before measurement 


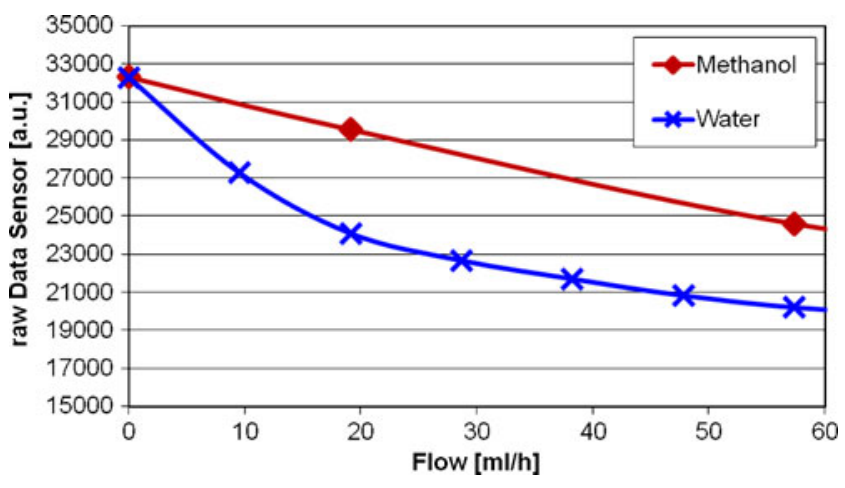

Fig. 12 Calibration curves of the CMOS calorimetric flow sensor for water and methanol. The shape of the response curve of the sensor strongly depends on the nonlinear influence of the thermal conductivity of the liquid used. The thermal conductivity of methanol is a factor of 2.9 smaller compared to water

The viscosity of blood at $37^{\circ} \mathrm{C}$ in fluidic channels with diameter bigger than $0.3 \mathrm{~mm}$ can reach values up to 3 times of the viscosity of plasma (at a haematrocrit value of 0.45 ). Blood as a non-newtonian fluid reaches viscosities $\eta$ of $3.26+/-0.43,4.37+/-0.60$, and $5.46+/-0.84 \mathrm{mPa}$.s at shear rates of 100,50 , and $1 \mathrm{~s}^{-1}$ at $37^{\circ} \mathrm{C}$ (Rosenson et al. 1996).

Compared to blood, the mean viscosity for plasma and serum in healthy adults are significantly lower with values of $1.39+/-0.08 \mathrm{mPa} \cdot \mathrm{s}$ and $1.27+/-0.06 \mathrm{mPa} \cdot \mathrm{s}$ respectively. The same is true for CSF which is a newtonian fluid reaching values in the range of $0.7-1 \mathrm{mPa} \cdot \mathrm{s}$ at $37^{\circ} \mathrm{C}$ (Water: $\eta=0.65 \mathrm{mPa} \cdot \mathrm{s}$ ) (Bloomfield et al. 1998). Bloomfield et al. investigated the effect of protein, erythrocytes and glucose on the viscosity of CSF and its consequent impact on shunt function. Protein concentration and viscosity values of CSF from patients were measured relative to an artificial CSF and distilled water values. The study concluded that increased protein levels did not significantly increase CSF viscosity.

Therefore the observed increase of flow rate in position "Horizontal Sensor Blood UP 1/2" in Fig. 11 when blood is added to artificial CSF in can be attributed to the change of viscosity of the liquid due to the sedimentation of heavier erythrocytes. The viscosity of this sediment becomes more elevated resulting in a lower flow rate near the bottom of the flow channel. Since the overall volume of the fluid passing through the channel is kept constant by the peristaltic pump, the flow rate at the top of the flow channel, where only the lower viscous CSF-plasma mix is flowing, increases accordingly. The decrease of flow rate in position "Horizontal Sensor Blood DOWN" in Fig. 11 can be explained by both a increased viscosity and reduced thermal conductivity of the blood sediment.

\section{Conclusions}

We presented a novel implantable flow transducer which is composed of a calorimetric flow sensor based on a thermal anemometer principle, a microcontroller and a RF section for passive telemetry and which can be implanted for the treatment of hydrocephalus.

The in-vitro characterization of the transducer with artificial CSF and artificial CSF where 10\% fresh blood was added did not show any drift which could be associated to a deposition of proteins even though the tested protein level of $2 \mathrm{~g} / \mathrm{l}$ in CSF was about 10 times higher than the normal protein level in human beings.

An offset of $-2 \%$ to $-10 \%$ with an average of $-5.4 \%$ which was found in the relative flow rate comparing the sensor reading and the scale measurement is due to the calibration of the sensors at room temperature versus the $37^{\circ} \mathrm{C}$ test temperature.

A comparison of relative flow rates at $22^{\circ} \mathrm{C}$ and $37^{\circ} \mathrm{C}$ gives a temperature offset of $6.3 \%$. A temperature compensation of the offset of $-5.4 \%$ at $37^{\circ} \mathrm{C}$ with the temperature offset of $+6.3 \%$ leads to a compensated average of all relative flow rates of $+0.9 \%$.

Even if a protein layer had been deposited on the flow channel wall during the 26 days of exposure of the in-vitro measurements, its thickness is not sufficient to have an influence on the sensor reading.

Measurements with varying positions and orientations of the sensor with respect to the flow channel indicate that blood which is not homogeneously mixed in the CSF can
Fig. 13 Comparison of the flow profile for artificial CSF (left) and for artificial CSF with $10 \%$ fresh blood (right). When fresh blood is added to artificial CSF, the erythrocytes settle down on the bottom of the flow channel which results in an asymmetric flow profile

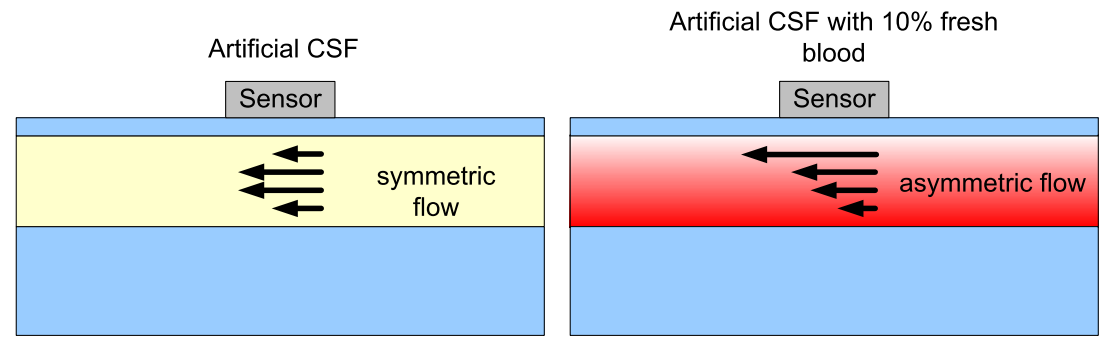


temporarily disturb the flow sensor reading. However in a real life situation this is not relevant as the patient is moving and the fluid remains mixed. Blood did not create any permanent changes of the sensor output due to deposition of blood components on the flow channel wall. The flow sensor specification requirement of $+-10 \%$ for a flow range between $2 \mathrm{ml} / \mathrm{h}$ and $40 \mathrm{ml} / \mathrm{h}$. could be confirmed at test conditions of $37^{\circ} \mathrm{C}$.

When observing visually the transparent tubing of the fluidic setup it was seen that the heavier blood components (erythrocytes, thrombocytes) were settling on the tubing bottom due to the low flow rate used. This sedimentation of heavier blood components on the channel bottom means that the viscosity of that sediment becomes more elevated compared to the remaining CSF/plasma mix resulting in a lower flow rate near the channel bottom. As the overall volume of fluid passing through the channel is kept constant by the peristaltic pump of the fluidic setup, the top of the flow channel where only the lower viscous CSF/ plasma mix is remaining, the flow rate on top of the sedimented erythrocytes increases (Fig. 13).

Most important, fresh blood added to the CSF with high protein concentration of $2 \mathrm{~g} / \mathrm{l}$ does not permanently adsorbed onto the sensing surface: Comparing the relative flow before the fresh blood was added and after the blood was removed, the same accuracy between $-5 \%$ and $-9 \%$ can be measured. That means that when the blood has passed there is no permanent influence of the blood remaining on the sensor reading. Furthermore this data falls well within the accuracy of the sensors which is in the range between $-2 \%$ and $-9 \%$.

The addition of $10 \%$ fresh blood to artificial CSF leads to an average increase of the relative flow rate of $+17 \%$ compared to the scale reference measurement in the configuration where the sensor is on the top of the flow channel and to an averaged decrease of $-53 \%$ compared to the scale reference measurement in the configuration where the sensor is at the bottom of the flow channel. The first corresponds to the situation where the sensor is in contact with a CSF/plasma mixture having an increased flow velocity and the latter corresponds to the situation where the sensor is in contact with the sedimented erythrocytes solution having an increased viscosity and reduced thermal conductivity. The observed asymmetry of relative flow rates in horizontal up- and down positions can be explained by the additional effect of reduced thermal conductivity of the blood sediment which is effective only when the sensor is in contact with the blood sediment in the horizontal down position and which further reduces the sensor signal. The velocity of the medium in vicinity to the sensing surface of the anemometric flow sensor depends on the detailed sedimentation profile of the mixture of artificial CSF and $10 \%$ whole blood.
The presented flow transducer has the potential to improve the quality of life of normal pressure hydrocephalus patient, by more accurate monitoring of the functioning of the valve and better understanding of CSF flow under different physiological conditions. An improved management of hydrocephalus shunted patients will be possible by avoiding conditions of over- or under-drainage of CSF.

Acknowledgements This research was supported by the Swiss innovation promotion agency (grant CTI \#8558.1 LSPP-LS). The authors would like to thank Dr. Roger Bayston for the recommendations concerning the test liquids and their preparation.

\section{References}

C. Baird, S. Farner, C. Mohr, T. Pittman, Pediatr. Neurosurg. 37(4), $186(2002)$

T.A. Balasubramaniam, H.F. Bowman, J. Biomech. Eng. 99, 148 (1977)

P.M. Black, R.G. Ojemann, A. Tzouras, Clin. Neurosurg. 32, 632 (1985)

I.G. Bloomfield, I.H. Johnston, L.E. Bilston, Pediatr. Neurosurg. 28 (5), 246 (1998)

T. Bork, Thermal Flow Sensor Having Streamlined Packaging, US Patent No. 7,181,963 B2 (2007)

H.L. Brydon, G. Keir, E.J. Thompson, R. Bayston, R. Hayward, W. Harkness, J. Neurol. Neurosurg. Psychiatry 64, 643 (1998)

M. Critchley, J.L. O'Leary, B. Jennett, Scientific Foundations of Neurology, 1st edn. (Heinemann Medical, London, 1972)

H. Davson, M.B. Segal, Physiology of the CSF and Blood-brain Barriers, 1st edn. (CRC, New York, 1996)

A. Ginggen, Method for brazing two glass components, European Patent No. EP1184351 (2003)

A. Ginggen, Y. Tardy, R. Crivelli, T. Bork, P. Renaud, Biomedical Engineering, IEEE Trans. Biomed. Eng. 55(4), 1374 (2008)

International Standards Organization (ISO) 14708-1. Implants for surgery-Active implantable medical devices-Part 1: general requirements for safety, marking and for information to be provided by the manufacturer (2000)

W.H. Ko, A.M. Leung, E. Cheng, R.J. Lorig, Biotelem. Patient Monit. 8(3), 131 (1981)

V. Kurtcuoglu, M. Soellinger, P. Summers, K. Boomsma, D. Poulikakos, P. Boesiger, Y. Ventikos, J. Biomech. 40, 1235 (2007)

W. Kuschinsky, in Comprehensive Human Physiology, Vol. 1, ed. by R. Greger, U. Windhorst (Springer, Berlin, 1996), p. 545

T.S.J. Lammerink, N.R. Tas, M. Elwenspoek, J.H.J. Fluitman, Sens. Actuators, A 37-38, 45 (1993)

A. Larsson, C. Wikkelsö, M. Bilting, H. Stephensen, Acta Neurol. Scand. 84, 475 (1991)

A.A. Linninger, M. Xenos, D.C. Zhu, M.R. Somayaji, S. Kondapalli, R.D. Penn, IEEE Trans. Biomed. Eng. 54(2), 291 (2007)

F. Lundberg, D.Q. Li, D. Falkenback, T. Lea, P. Siesjö, S. Söderström, B.J. Kudryk, J.O. Tegenfeldt, S. Nomura, A. Ljungh, J. Neurosurg. 90, 101 (1999)

F. Mayer, A. Häberli, H. Jacobs, G. Ofner, O. Paul, H. Baltes, Proc. IEEE International Electron Device Meeting IEDM 97, IEEE 1997, p. 895-898. (1997)

F. Mayer, M.R. Hornung, R.S. Vanna, Flow sensor, US Patent No. 6813944 (2004)

I. Munshi, D. Lathrop, J.R. Madsen, D.M. Frim, Pediatr. Neurosurg. 28, 67 (1998) 
W.R. Murshid, J.S. Jarallah, M.I. Dad, Pediatr. Neurosurg. 32, 119 (2000)

S. Neff, J. Neurosurg. Pediatr. 4 103(4 Supp.I), 366 (2005)

P.A. Neukomm, D. Furrer, Proceedings of the 17th Conference of the International Society on Biotelemetry ISOB 17, Brisbane 1 - 5 September (2003)

J. Oikonomou, A. Aschoff, B. Hashemi, S. Kunze, Eur. J. Pediatr. Surg. 9(Suppl. I), 23 (1999)

E.-K. Persson, S. Anderson, L.-M. Wikl, P. Uvebrant, Child's Nerv. Syst. 23(10), 1111 (2007)

R.S. Rosenson, A. McCormick, E.F. Uretz, Clin. Chem. 42, 1189 (1996)
U. Schnakenberg, P. Walter, G. vom Bögel, C. Krüger, H.C. LüdtkeHandjery, H.A. Richter, W. Specht, P. Ruokonen, W. Mokwa, Sens. Actuators, A 85(1-3), 287 (2000)

S. Sgouros, P. John, A.R. Walsh, Childs Nerv. Syst. 12, 454 (1996)

J.A.L. Vanneste, J. Neurol. 247, 5 (2000)

J. Vanneste, P. Augustijn, C. Dirven, W.F. Tan, Z.D. Goedhart, Neurology 42, 54 (1992)

J. Vassilouthis, J. Neurosurg. 61, 501 (1984)

S. Widell, Acta Paediatr. 47(suppl. 115), 1 (1958)

M. Wong, B.L. Schlaggar, R.S. Buller, G.A. Storch, M. Landt, Arch. Pediatr. Adolesc. Med. 154, 827 (2000) 